\title{
Acetylation and sugar composition influence the (in)solubility of plant $\beta$-mannans and their interaction with cellulose surfaces
}

\section{Supporting information}

Jennie Berglund ${ }^{\dagger *}$, Saina Kishani ${ }^{\# \#, ~ D a n i l a ~ M o r a i s ~ d e ~ C a r v a l h o ~}{ }^{\dagger}$, Martin Lawoko ${ }^{\dagger \#, ~ J a k o b ~}$ Wohlert ${ }^{\dagger \#}$, Gunnar Henriksson ${ }^{\dagger \#}$, Mikael E. Lindström ${ }^{\dagger \#, ~ L a r s ~ W a ̊ g b e r g ~}{ }^{\ddagger \#}$, Francisco Vilaplana ${ }^{\S * *}$

†Department of Fibre and Polymer Technology, School of Engineering Sciences in Chemistry, Biotechnology and Health, KTH Royal Institute of Technology, 10044 Stockholm, Sweden.

${ }^{\circledR}$ Division of Glycoscience, Department of Chemistry, School of Engineering Sciences in Chemistry, Biotechnology and Health, KTH Royal Institute of Technology, AlbaNova University Centre, 10691 Stockholm, Sweden

\#Wallenberg Wood Science Centre, KTH Royal Institute of Technology, 10044 Stockholm, Sweden.

$\$$ These authors contributed equally to the work

* Corresponding author: Francisco Vilaplana (franvila@kth.se) 
Table S1. Total amounts $(\mathrm{ml})$ of added acetic anhydride $\left(\mathrm{Ac}_{2} \mathrm{O}\right)$ to the model acetylated mannan sample at the consecutive time intervals

\begin{tabular}{|c|c|c|c|c|}
\hline Sample & $0 \mathrm{~h}$ & $1 \mathrm{~h}$ & $23 \mathrm{~h}$ & Total \\
\hline $\mathrm{KGM}_{\text {low }}$ & 1 & 1 & 1 & 3 \\
\hline $\mathrm{KGM}_{\text {mid }}$ & 3 & 3 & 2 & 8 \\
\hline $\mathrm{KGM}_{\text {high }}$ & 4 & 4 & 4 & 12 \\
\hline $\mathrm{LBG}_{\text {low }}$ & 0.45 & 0.45 & 0.45 & 1.35 \\
\hline $\mathrm{LBG}_{\text {mid }}$ & 1.35 & 1.35 & 1.35 & 4.05 \\
\hline $\mathrm{LBG}_{\text {high }}$ & 5 & 5 & 2 & 12 \\
\hline
\end{tabular}


Table S2. Probability and standard error for respective molecule and region.

\begin{tabular}{cccc}
\hline Molecule and linkage & \multicolumn{3}{c}{ Probability in \% (standard error) } \\
\cline { 2 - 4 } & Region 1 & Region 3 & Region 4 \\
\hline MM-WM & $3.2(1.0)$ & $7.8(0.6)$ & $89(0.9)$ \\
\hline MMY-M & $1.2(0.4)$ & $1.2(0.2)$ & $97.6(0.3)$ \\
\hline MY-WM & $0(0)$ & $1.4(0.3)$ & $98.6(0.3)$ \\
\hline MM-TM & $1(0.4)$ & $6.6(0.6)$ & $92.4(0.6)$ \\
\hline MMT-M & $2.2(0.8)$ & $0.9(0.2)$ & $96.8(0.8)$ \\
\hline MM-MM & $2.5(1.2)$ & $5.7(0.2)$ & $91.7(1.2)$ \\
\hline MMM-M & $1(0.5)$ & $5.3(0.3)$ & $93.7(0.4)$ \\
\hline
\end{tabular}


Table S3. Water fraction of the adsorbed mass obtained in QCM study.

\begin{tabular}{|c|c|c|c|}
\hline $\begin{array}{c}\text { Water fraction } \\
\%\end{array}$ & $\begin{array}{c}\mathrm{DS}_{\mathrm{ac}} \\
(\mathrm{raw})\end{array}$ & $\begin{array}{c}\mathrm{DS}_{\mathrm{ac}} \\
(\mathrm{Low})\end{array}$ & $\begin{array}{c}\mathrm{DS}_{\mathrm{ac}} \\
(\mathrm{Mid})\end{array}$ \\
\hline LBG & 2.6 & 3.2 & 0.6 \\
\hline KGM & - & 0.4 & 1.1 \\
\hline GGM2 & - & 1.1 & - \\
\hline
\end{tabular}




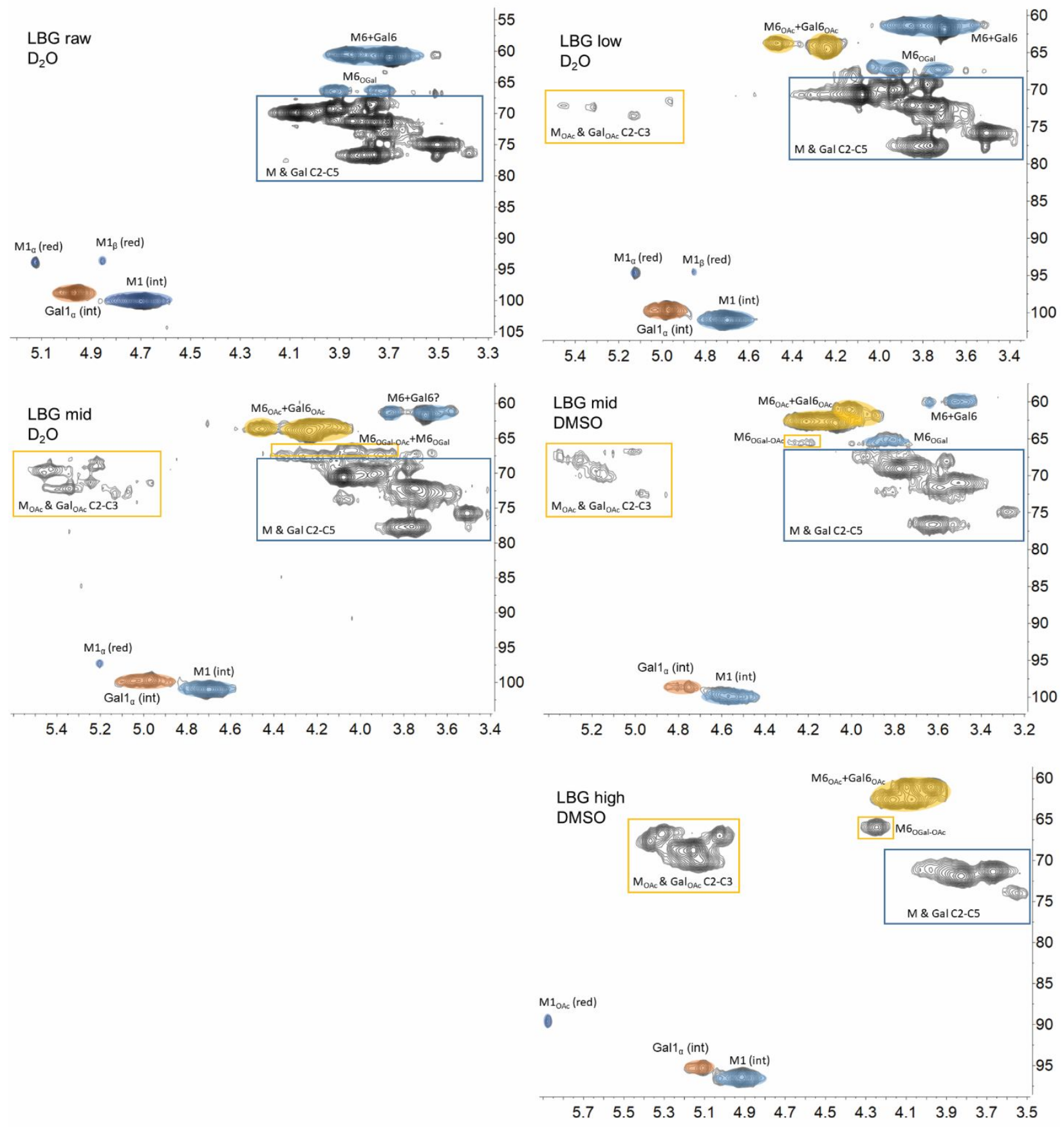

Figure S1. 2D NMR (HSQC) LBG samples. A yellow box or yellow peak corresponds to acetylated carbons $(\mathrm{C})$. When the ratios are estimated the area of $\mathrm{C} 6$ is divided with 2 due to the influence from two hydrogens on the area. Orange is for galactose (Gal) and blue for mannose (M) as well as overlapping Gal and M peaks. The number in the name corresponds to the carbon. 


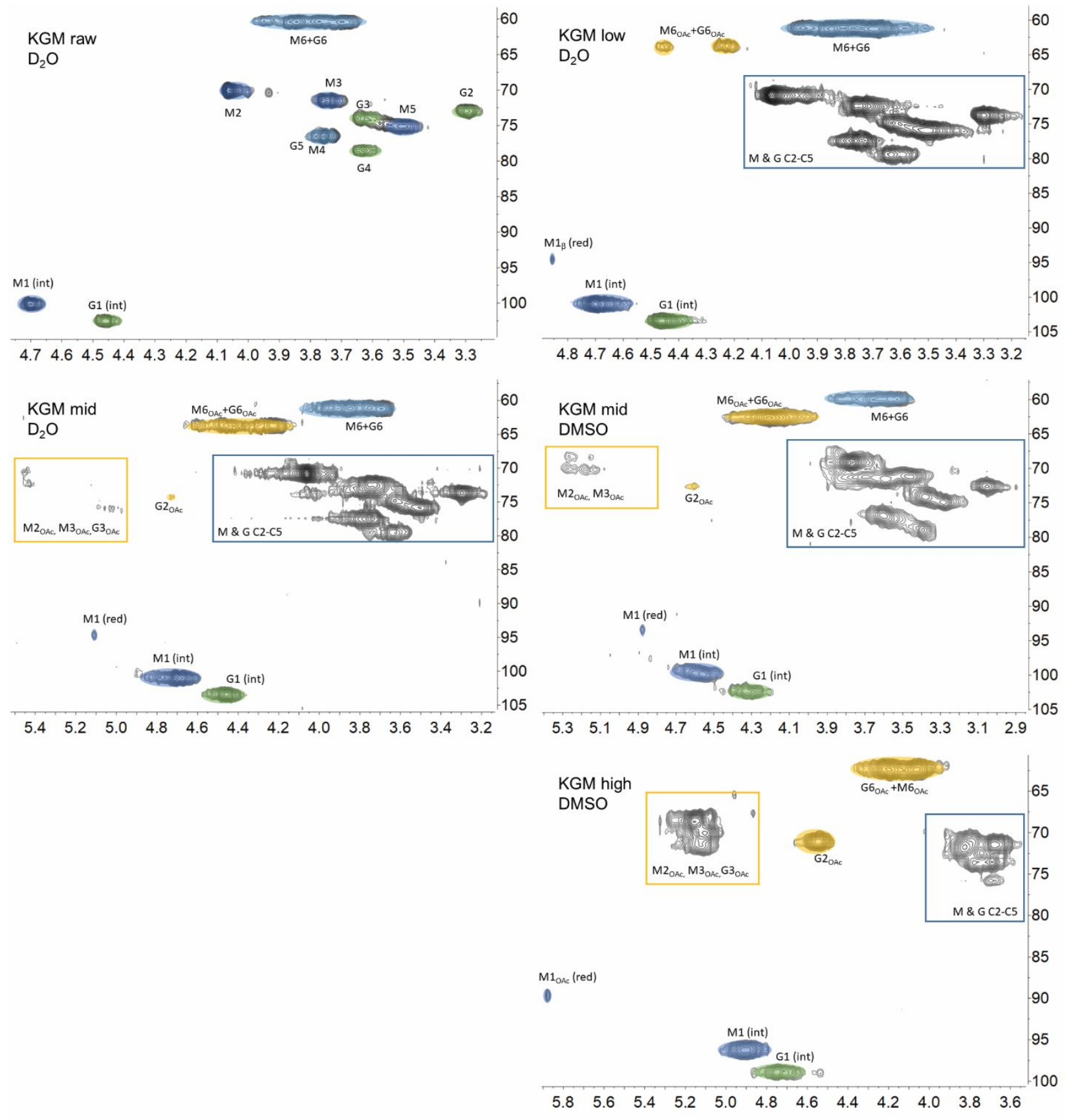

Figure S2. 2D NMR (HSQC) KGM samples. A yellow box or yellow peak corresponds to acetylated carbons (C). When the ratios are estimated the area of C6 is divided with 2 due to the influence from two hydrogens on the area. Green is for glucose $(\mathrm{G})$ and blue for mannose (M) as well as overlapping $\mathrm{G}$ and $\mathrm{M}$ peaks. The number in the name corresponds to the carbon. 


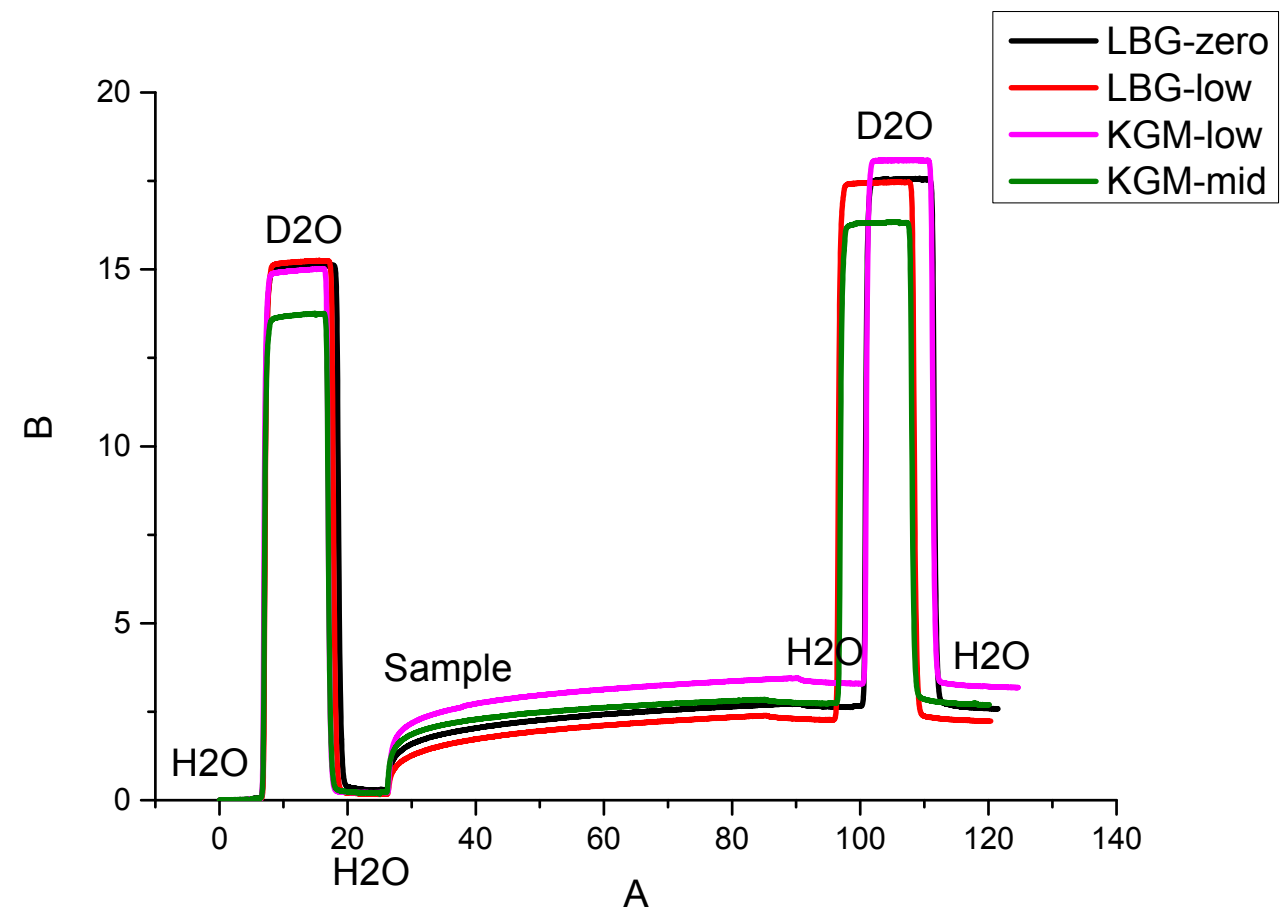

Figure S3. QCM-D data showing the solvent exchange from water $\left(\mathrm{H}_{2} \mathrm{O}\right)$ to deuterium oxide $\left(\mathrm{D}_{2} \mathrm{O}\right)$. 